\title{
LIBERTY, EFFICIENCY, AND LAW
}

\author{
ROBERT D. COOTER*
}

I

\section{INTRODUCTION}

Unlike the legislators, judges must offer official explanations for their decisions that are carefully scrutinized by the bar and academics. The process of adjudication thus emphasizes cogency and reasonableness. The reasons given by judges for their decisions are bewildering in their complexity: equity, fairness, efficiency, clarity, administrability, precedent, and morality, to name a few, jostle each other for prominence. Any attempt to arrange these values in order of priority risks distorting the law. It is, however, the task of theorists to reduce complex facts to simple explanations. Theorists are to be forgiven, even praised, for trying to reduce the bewildering particularity of the law to a modest number of coherent abstractions, even though their efforts never entirely succeed.

This article concerns the relationship between fundamental legal values and the economic analysis of law. Much of applied welfare economics, including cost-benefit analysis, takes as its objective increasing the wealth of society. This approach has been applied to law with considerable success by economists, whose practice has been raised to the level of principle-the principle that the law ought to maximize wealth-by philosophically inclined theorists, notably Richard Posner. ${ }^{1}$ Reducing the complex purposes of the common law to a single, abstract value is an heroic project. One understanding of this project is that wealth is the most fundamental legal value. This article, however, offers a different understanding of the economic analysis of law.

Most concepts of economic efficiency assume an initial distribution of resources as a starting point. An initial distribution of resources is needed to supply the prices that are used to reduce different goods to a single metric for purposes of comparing their value. Once prices are given, it is possible to ask whether a particular policy increases or decreases value. When this framework is applied to law, the initial distribution of resources corresponds to the fundamental rights and duties that law assigns to people. These rights and duties may be characterized as normative resources. The efficiency analysis of law, as the present author understands it; takes as its objective

Copyright $\odot 1988$ by Law and Contemporary Problems

- Professor of Law, University of California, Berkeley, California.

1. R. Posner, The Economics of Justice (1981); see also Symposium: The Implications of Social Choice Theory for Legal Decisionmaking, 9 Horstra L. Rev. 1373 (1981). 
maximizing the value of these normative resources as measured by the preferences of the people to whom they are initially allocated.

Since the efficiency analysis of law cannot turn upon itself and prove what it assumes, economists must wonder how they are to understand an initial distribution of normative resources. One approach is to treat an initial distribution as an historical artifact. This approach is congenial to skeptics who accept that norms can be described, but doubt whether they can be explained or justified. Another approach taken in jurisprudence is to offer a philosophical justification and critique of fundamental legal values. This approach is congenial to philosophically inclined legal scholars. Regardless of the approach, once an initial distribution of legal rights and duties is described, the efficiency analysis can show how to maximize its value. This is important in principle and useful in practice. There is, then, a division of labor in legal studies: Jurisprudence or history provides an account of basic normative resources, while economics shows how to maximize their value.

Instead of discussing fundamental legal values in general, this article focuses upon the particular value of liberty. Liberty is so important that some philosophers postulate that it is, or should be, the paramount legal value. According to John Rawls, for example, the first principle of a just society is to maximize the amount of basic liberty that everyone enjoys equally. ${ }^{2}$ In section II, this article explains what it means to maximize liberty, which is an important topic slighted by philosophers. This explanation puts theories of liberty into the perspective of microeconomics. Section III explains the natural affinity between liberty and the most fundamental standard of evaluation in economics, Pareto efficiency. ${ }^{3}$ There is in contrast to this affinity a potential antagonism between liberty and wealth as social goals, which is also explained in section III. The conclusion is reached that American law is more concerned with maximizing liberty, which is closely connected to rightsbased theories of law, than with maximizing wealth, which is closely linked to utilitarianism and materialism.

\section{II}

\section{Three Concepts of Liberty}

Political theorists who stress liberty tend to prefer a government that provides its citizens with more of it rather than less. Such a preference presupposes the ability to order governments according to the amount of liberty afforded to their citizens. Philosophers have not, however, paid careful attention to constructing the ordering. Section II of this article is devoted to filling in the gap. Three different ways will be described for scaling the

2. J. Rawls, Theory of Justice 60 (1971) ("Each person is to have an equal right to the most extensive basic liberty compatible with a similar liberty for others.").

3. See infra at 151 for definitions of the terms "Pareto improvement" and "Pareto efficiency." These concepts are discussed in all basic microeconomics texts. For an introductory explanation, see E. Mansfield, Microeconomics 367 (1979). For a more advanced treatment, see H. Varian, Microeconomic Analysis 145, 216 (1978). 
conventional liberties and identifying a maximum set. No attempt will be made, however, to choose among competing concepts of liberty in the philosophical tradition, or to defend a particular theory of liberty against rival conceptions, but they will be distinguished sufficiently to show how they rank alternative governments.

\section{A. Liberty-As-Permission}

The simplest concept of liberty is the absence of prohibitions. To clarify this idea, imagine a set consisting of all possible acts that government partitions into permitted and forbidden zones, as shown in Figure 1. Individuals are free to do the acts in the permitted zone and they are not free to do any of the forbidden acts. The size of the forbidden zone determines the scope of government regulation and control. The extent of liberty, under the simplest conception, is determined by the size of the permitted zone. The present author calls this conception "liberty-as-permission."

A ranking of governments by the extent of liberty enjoyed by their citizens, where liberty is understood as permission, is generated by forming subsets within the permitted set. Suppose, for example, that Government B permits all actions that are allowed by Government $A$, except that the press is censored in B and free in $A$. The permitted zone under Government B, consequently, lies entirely within the permitted zone under Government A. Since the former is a subset of the latter, there is more liberty-as-permission under Government A than under Government B, as shown in Figure 2.

The comparison between Government A and Government B illustrates that liberty-as-permission can order some alternative governments by the extent of liberty, ${ }^{4}$ so phrases like "maximum liberty" have a clear meaning. This representation of liberty is, however, deficient in many respects. ${ }^{5}$ Any prohibition diminishes liberty-as-permission, regardless of whether the prohibited act is printing or raping. Press censorship restricts freedom, but it seems peculiar to say the same about rape. The peculiarity of speaking as if laws prohibiting rape restrict freedom betrays a peculiar way of thinking. Liberty is not the same as license to harm others. Taking account of this fact requires a description of liberty that is more complicated.

\section{B. Liberty-as-No-Interference}

To distinguish printing from raping, liberty must consist, not in the permission to do any act, but in the permission to do acts that do not interfere with others. Under this conception the amount of liberty is measured by the

4. The ordering is partial because not all governments can be ranked by this standard. Two governments can be ranked as long as the permitted zone of one is contained in the permitted zone of the other, but they cannot be ranked by this standard when the permitted zone of one is not contained in the permitted zone of the other.

5. Here are two examples of deficiencies omitted in the article's text. Voting is an act created by government. Are such acts included in the set depicted in Figure 1? Many activities are highly regulated but not forbidden outright. On which side of the partition in Figure 1 are they? 


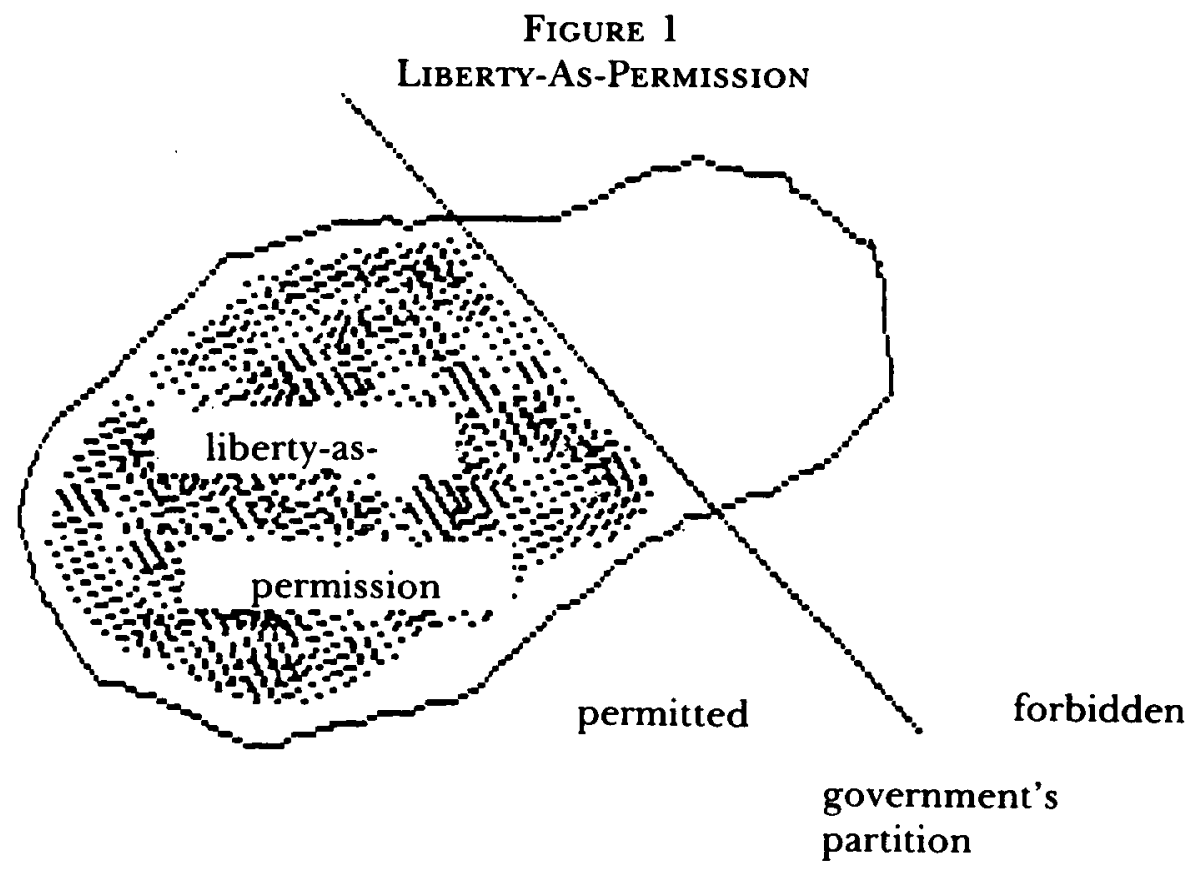

Set of Possible Acts

number of noninterfering acts that are permitted. To illustrate graphically, imagine that the set of all possible acts is partitioned into those that interfere with others and those that do not interfere with others, as shown in Figure 3.

\section{Figure 2 \\ CoMparing LiberTy-As-Permission}

$\because$ permitted by Government B

If permitted by Government A

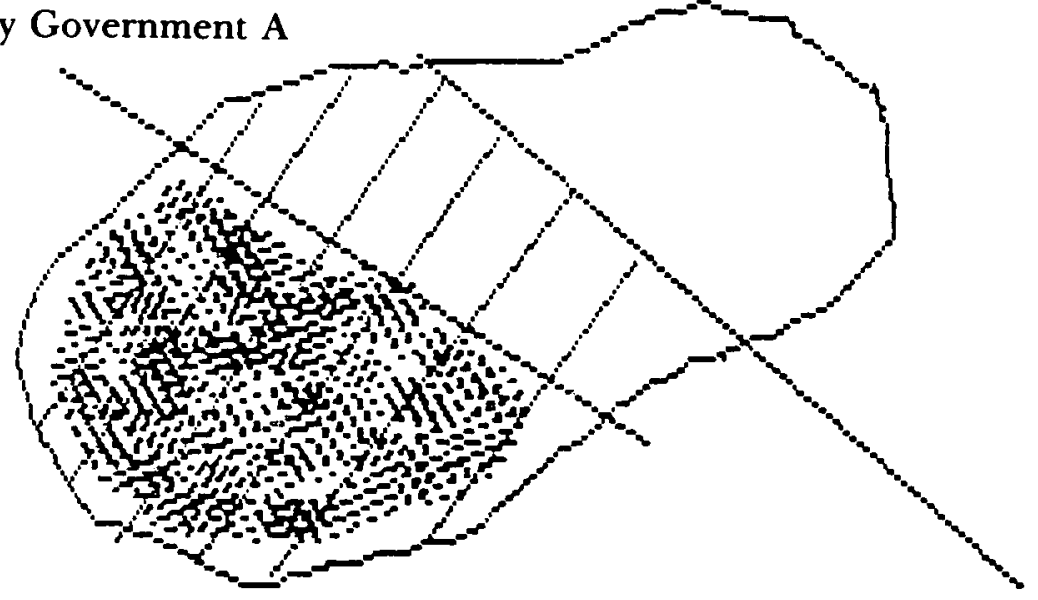

Set of Possible Acts 
There is, in addition, another partition between permitted acts and forbidden acts. According to liberty-as-no-interference, the amount of liberty depends

Figure 3

\section{LIBERTY-As-NO-INTERFERENCE}

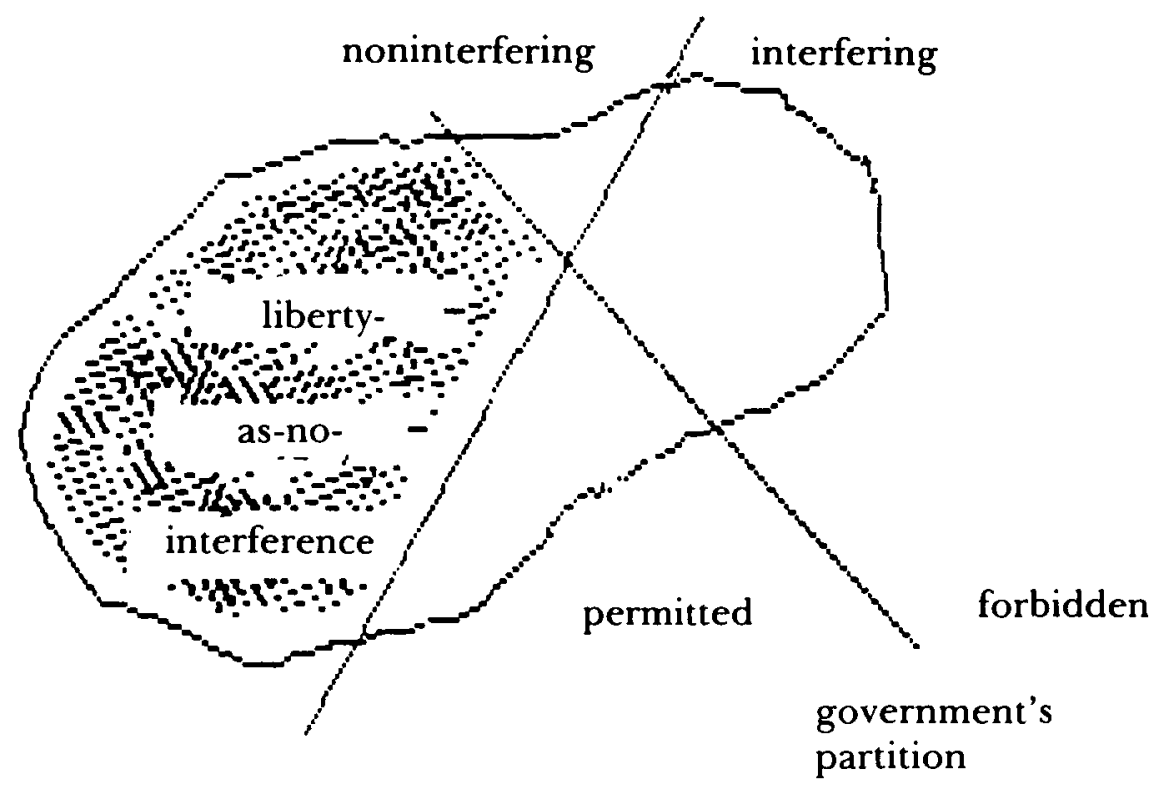

Set of Possible Acts

upon the extent of the intersection between the set of permitted acts and the set of noninterfering acts, which is shaded in Figure $\mathbf{3}$.

The two concepts of liberty-liberty-as-permission and liberty-as-nointerference-can be contrasted by the use of concrete examples. Consider again Governments $A$ and $B$, which are identical except that the press is censored in B and free in A. There is more liberty-as-permission in A than in B. Publishing is, presumably, a noninterfering act, so there is also more liberty-as-no-interference in A than in B. In contrast, suppose that Governments $C$ and $D$ are alike except that Government $C$ prohibits rape and Government $\mathrm{D}$ permits it. There is more liberty-as-permission in $\mathrm{D}$ than in $\mathrm{C}$. Rape, however, is included among the acts whereby one person interferes with another (to put it mildly), so liberty-as-no-interference is not greater in D than in $\mathrm{C}$. The two concepts of liberty-liberty-as-permission and liberty-asno-interference-rank $A$ and $B$ the same, and they rank $C$ and D differently. ${ }^{6}$

6. It is the author's view that forbidding a noninterfering act reduces liberty-as-nointerference. The reader may wonder whether permitting an interfering act, such as rape, also 
Liberty-as-no-interference is maximized when all noninterfering acts are permitted. This is apparently the principle Mill enunciated in his classic, On Liberty:

The object of this Essay is to assert one very simple principle, as entitled to govern absolutely the dealings of society with the individual in the way of compulsion and control, whether the means used be physical force in the form of legal penalties, or the moral coercion of public opinion. That principle is, that the sole end for which mankind are warranted, individually or collectively, in interfering with the liberty of action of any of their number, is self-protection. That the only purpose for which power can be rightfully exercised over any member of a civilized community, against his will, is to prevent harm to others. His own good, either physical or moral, is not a sufficient warrant . . . 7

What counts as harm or interference? This is the crux of Mill's theory. Mill wrote in a utilitarian tradition of thought that measures harm in utils. Utility was understood as a psychological value similar to pleasure or happiness. ${ }^{8}$ In so far as Mill was a utilitarian, the harm contemplated by him is presumably pain or unhappiness. Interfering with others, according to a utilitarian conception, involves inflicting pain or causing unhappiness. ${ }^{9}$

The utilitarian conceptions of harm and interference can be updated in light of subsequent developments in economics. In modern economics, the utilitarian theory of value has been replaced by a logic of choice. ${ }^{10}$ Choices can be ordered from bad to good according to a decisionmaker's preferences, and the real numbers can be ordered from small to large. A utility function in modern economics merely associates better choices with larger numbers. This association conforms to certain rules of consistency, but it is neutral with respect to the values that are the basis of the preference ordering. Instead of understanding "utility" as a psychological value, the term as used in modern economics denotes an assignment of numbers to express a preference ordering. Like Mill, modern economics stresses respect for each person's

reduces liberty. The answer is that interfering acts harm others, but the harm does not necessarily take the form of restricting their liberty.

7. Shields, Introduction to J. Mill, ON LiberTy 13 (C. Shields ed. 1956).

8. Lafleur, Introduction to J. Bentham, An Introduction to the Principles of Morals and LEGisLATION 2 (1973) ("By utility is meant that property in any object, whereby it tends to produce benefit, advantage, pleasure, good, or happiness, (all this in the present case comes to the same thing) or (what comes again to the same thing) to prevent the happening of mischief, pain, evil, or unhappiness to the party whose interest is considered ....").

9. Another definition of harm, different from pain or interference, should be mentioned. Suppose a set of norms defines the duties people owe to each other. Failing to fulfill one's duty to others is sometimes said to cause moral harm. This kind of harm is normative because it consists of the breach of a moral duty owed to the victim. Mill's principle states that moral rules cannot be enforced against the individual unless violating them harms someone. If the harm referred to in Mill's principle encompassed moral harm, almost every moral rule would pass the principle's test. This fatal circularity, which trivializes Mill's principle by smuggling all of morality into it, is avoided by a nonnormative definition of harm. To illustrate, if homosexual acts between consenting adults are a source of pleasure to those who engage in them, and no pain or unhappiness is inflicted upon people, Mill's principle would strike down laws prohibiting such acts, even though many people feel that the actors are morally harmful.

10. J. Schumpeter, History of Economic Analysis 1058 (1967) (“[T]he utility theory of value has much better claim to being called a logic than a psychology of values."). 
preferences. Everyone is left to be the judge of his or her own pleasure or happiness, and paternalistic interference with others is deemed inappropriate.

Contemporary economics also contains a concept similar to interference as contemplated in Mill's essay, specifically the concept of an externality. An externality exists when the utility functions or production functions of different decisionmakers are interdependent." ${ }^{11}$ To illustrate, a factory's output of smoke directly lowers the utility of people who live nearby and breathe the air. Direct interdependency in utility or production functions bypasses markets and causes socially undesirable effects. Externalities are one form of market failure that economists cite to justify regulation, ${ }^{12}$ whereas the absence of externalities is cited as a reason for not interfering with the market. This prescription can be translated directly into Mill's terms: When decisionmakers do not harm each other, the state should not regulate their behavior, but when one person's choice harms another, regulation may be appropriate. ${ }^{13}$ The proposition that perfectly competitive markets should not be regulated resembles Mills' proposition that noninterfering acts should not be restricted. Mill denies the enforceability of moral rules that restrict liberty, much like economists rail against regulations that restrict competition.

\section{Are There Any Noninterfering Acts?}

Liberty is one value among many in a normative system. Mill's principle uses this value to restrict the reach of competing values, especially competing moral rules. In Mill's system, liberty trumps all restrictions upon acts that do not interfere with other people. There are several ways in which to criticize Mill's principle. ${ }^{14}$ One way is to assert that few acts are noninterfering. If the set of noninterfering acts is small, Mill's principle amounts to nothing. This is similar to the proposition that if externalities are extensive, the model of perfect competition amounts to nothing. Several reasons can be advanced

11. Interdependence in utility or production functions can be called a "material" externality, because it is imbedded in taste and technology. This kind of externality causes one person's behavior to interfere with another's. Eliminating a material externality requires changing taste or technology. Another kind of externality, which could be called an "incentive" externality, exists when people do not have to pay the full cost of the harm they do to others. Incentive externalities can be eliminated by getting incentives for efficient behavior. The two types of externalities are often confused because a material externality usually creates an incentive externality.

12. The market failures approach to regulation is developed by Charles Schultze in The Public Use of Private Interest (1977). For an opposing view, see Coase, The Problem of Social Cost, 3 J. L. \& ECON. 1 (1960).

13. The principle that a person who causes harm should compensate the victim is considered to be central to tort law and property law by many scholars. See, e.g., Epstein, $A$ Theory of Strict Liability, 2 J. Legal Stud. 151 (1973); Fletcher, Fairness and Utility in Tort Theory, 85 HARv. L. Rev. 537 (1972). Coase attacked the view that causality is a guide to the efficient assignment of liability. See Coase, supra note 12 , at 1 passim.

14. There are forms of legal coercion not contemplated by Mill's principle, such as the enforcement of contracts. Contracts are enforced to produce a positive good, such as better planning and coordination of behavior, not to avert harm. Furthermore, the reliance of Mill's principle upon a nonnormative account of harm works for tangible, material harms such as personal injuries. Whether it can work for intangible harms like defamation is problematic. To have adequate scope, Mill's principle may need to encompass some forms of normative harm and rely upon a thin theory of goodness, especially where harm to property is concerned. 
why the set of noninterfering acts might be small. The most immediate argument invites us to imagine a society of busy-bodies. They are so meddlesome that they perceive innocent acts as rife with potential harm to others. Their utility functions are hopelessly entangled. The scope for application of Mill's principle under their idea of noninterference is nil. This caricature resembles some closed communities, especially some religious communities. The members of such a community may feel that their lives should be regulated in intimate detail for their own perfection and to preserve shared values.

The busy-body argument against Mill is based upon entangled preferences. There is an argument based upon entangled resources that reaches the same conclusion. Many activities use resources directly and indirectly. Expressions of liberty, according to this argument, use resources directly that belong to others. The following example elucidates this principle. A printing press requires paper, which is a direct use of resources, and presses must be protected from thieves, which uses resources indirectly. A printer pays for his own paper but not for the police protection provided by the state, which is financed out of general tax revenues. Taxing people restricts their opportunities and interferes with their use of wealth. Accordingly, some resources required to exercise freedom of press must be obtained by interfering with others. Since the exercise of resource-using liberties interferes with other people, and since most liberties are resource-using, directly or indirectly, the set of noninterfering acts is very small. ${ }^{15}$ If the set of noninterfering acts is very small, a theory of liberty built upon it, like Mill's, would have little scope.

\section{Conjunctive Liberty}

There are several replies to the claim that preferences and resources are thoroughly entangled. ${ }^{16}$ It is not this author's purpose, however, to resolve the dispute about the size of the noninterfering set, but rather to examine its

15. There is a conventional distinction between positive and negative liberties. The negative liberties, like free speech, do not use public resources as intensively as the positive liberties, such as the right to a paid vacation. Jeremy Waldron argues that even negative liberties must be protected and fostered by expenditures of public resources. See J. Waldron, Property and Liberty (forthcoming, 1988).

16. Utilitarians can use the following argument to rebut the conclusion that law should respect busy-body preferences. Moral and civil laws should be evaluated according to their effect upon the pleasure and happiness of people. Once laws are in place, their violation becomes a source of displeasure in itself. To illustrate, if the speed limit in a residential neighborhood is 30 miles per hour, the residents will resent anyone driving 35 miles per hour. Resentment is second order in the sense that, since it is directed at rule breakers, it presupposes rules. If the speed limit were raised to 35 miles per hour, resentment towards drivers who go 35 miles per hour would probably dissipate, although residents might be annoyed by the higher speed limit.

Much of the displeasure that busy-bodies feel when others violate norms is second order and it would disappear if the norms were extinguished. So, when deciding whether or not to restrict peoples' liberty by recognizing busy-body norms, utilitarians ought to object to giving weight to second order displeasure.

As for entangled resource use, microeconomics has gotten along quite well all these years by assuming substantial separation in production functions. 
implications for maximizing liberty. When preferences and resources are entangled, a theory of liberty with general scope must focus upon the set of interfering acts. To permit one person to interfere with another is to deny someone protection from interference. There is a trade-off within the set of interfering acts between the exercise of liberty by one person and the protection of others. If, when measuring the extent of liberty, freedom to act and freedom from interference count equally, the amount of liberty is invariant. This is a zero-sum world, and, when a sum is fixed, it cannot be maximized.

How can the phrase "maximum liberty" be given meaning in a context of interfering acts? One way to resolve this dilemma is by assigning different weights to different acts. In order to speak of maximum liberty, different weights must be assigned to freedom from interference and freedom to act. To illustrate, the freedom to smoke competes with the freedom of nonsmokers to breathe clear air. Weight could be assigned to the competing rights to reflect their priority. Thus the right to smoke in one's own home may receive heavy weight, and, conversely, the right to be free from smoke in public places may also receive heavy weight. In extreme cases, no weight might be assigned to an act; the rapist's freedom might receive no weight relative to the right to be unmolested, for example. The phrase "conjunctive liberty" is used to describe a conception of liberty according to which the extent of liberty is measured as a weighted sum of different kinds of permitted acts.

Assigning weights to different acts requires a criterion for their differentiation. One approach that appeals to modern philosophers is to assign weights according to the centrality of the act to the development of personality. For example, Rawls conceives of people as rational agents who choose among different conceptions of goodness and plan their lives. This conception of the person stresses, first, the centrality of the freedom to evaluate and choose among competing conceptions of goodness, and second, access to the resources needed to pursue the specific plans that are framed. ${ }^{17}$ The freedom to choose among competing conceptions of goodness is the subject of a theory of liberty. This freedom is protected in the American constitution by the Bill of Rights, which guarantees such conventional liberties as freedom of speech, freedom of press, freedom of religion, and freedom of assembly. Liberty could be identified with the conjunction of these basic freedoms, as shown in Figure $4 .^{18}$

17. Access to the resources needed to pursue specific plans depends in part upon distributive justice, which is not the subject of this article, and in part upon efficiency, including efficient laws as discussed in this article.

18. A conjunction is a sum of items in a list. Notice that conjunctive liberty and liberty-as-nointerference reverse the relationship between the general concept of liberty and the particular liberties. Under conjunctive liberty, the general concept "liberty" means nothing more than the sum of the particular liberties; the particular liberties are logically independent and liberty is logically dependent. Under liberty-as-no-interference, there is a general conception of liberty-permission to do whatever does not harm others-and the individual liberties are all actions satisfying this 
Figure 4

Conjunctive Liberty

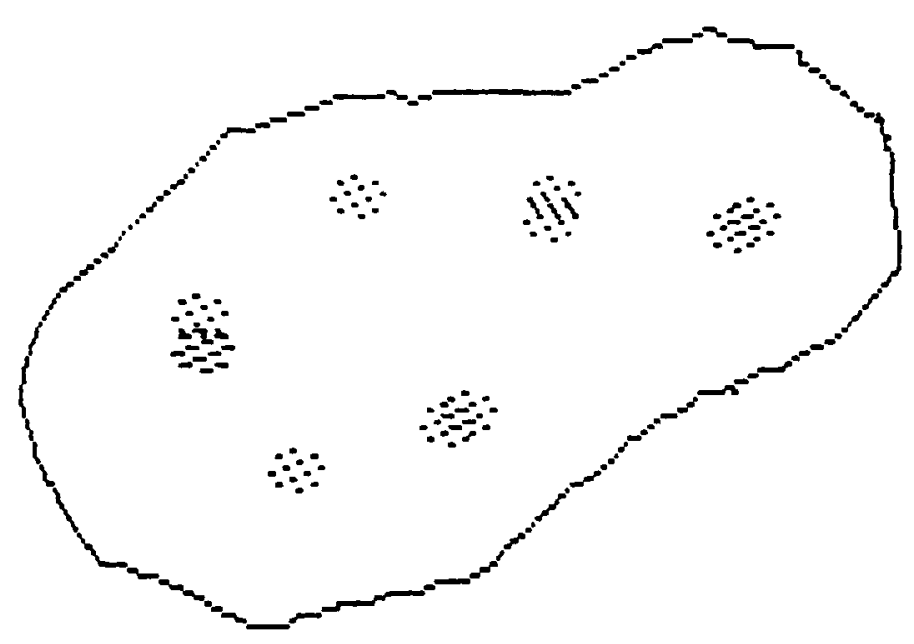

Set of Possible Acts

Maximizing conjunctive liberty is a matter of making the weighted sum of permitted acts as large as possible. Rawls' theory provides one example of how to give weight to competing liberties based upon the concept of a free, rational person. There are other standards for assigning these weights that either embody a different conception of a free person or emphasize other considerations. ${ }^{19}$ The various conceptions of liberty converge on some judgments about specific rights and diverge on others. From a philosophical viewpoint, the concept of conjunctive liberty lumps together different traditions; for the purposes of this article, however, it is not necessary to distinguish among them.

\section{III}

\section{EFFICIENCY AND LIBERTY}

This article has distinguished three conceptions of liberty according to formal methods of ranking governments by the extent of liberty afforded to their citizens. These conceptions give meaning to the phrase "maximum liberty." A conception of liberty is one source of fundamental rights and duties. This section explains how an efficiency analysis can maximize the value of these normative resources.

criterion; the general concept of liberty is thus logically independent and the particular liberties are logically dependent.

19. For example, Robert Nozick set out a theory in ANARchy, State, and Utopia (1974) that contrasts sharply with Rawls' theory. 


\section{A. Pareto Efficiency and Wealth}

Most economic models take efficiency as their objective, especially Pareto efficiency. A change is defined as a Pareto improvement if someone is made better off and no one is made worse off; Pareto efficiency is achieved when the scope for Pareto improvements is exhausted. "Better off" and "worse off" are measured relative to each person's well-being under an initial distribution of resources.

New policies and laws produce losers as well as winners, so it is almost impossible in practice to identify new policies or new laws that make someone better off without making anyone worse off. This fact is even more apparent in litigation than in legislation. In litigation, there is a disagreement over how to distribute the stakes in dispute. When the court reaches a decision about how to distribute the stakes, the holding in the case creates incentives for future behavior. When viewed retrospectively, resolving a legal dispute distributes the stakes, and when viewed prospectively, resolving a legal dispute creates incentives that may be efficient or inefficient.

The retrospective viewpoint usually dominates in the eyes of the litigants, who care more about distribution than efficiency. To illustrate, suppose that a pedestrian who is struck by a car sues the motorist. Further, suppose that the court contemplates abandoning the traditional rule of negligence with a defense of contributory negligence and adopting the new rule of comparative negligence in its stead. The expected liability of the defendant is less under the old rule than under the new rule, ${ }^{20}$ so the defendant will probably argue for the old rule. In spite of this fact, the defendant might prefer that all future disputes be decided under the new rule of comparative negligence. ${ }^{21}$ Automobile accidents happen so seldom that the future interest of the defendant in efficiency is overwhelmed by the distributional consequences of the present dispute.

Because litigation has distributive consequences, a particular holding usually makes someone worse off than an alternative holding within the court's ambit. This is why the literal Pareto standard is impractical as a guide to adjudication. The Pareto standard must be modified to have practical value for courts. The conventional modification is to allow changes for which the winners win more than the losers lose. So long as the winners win more than the losers lose, the former would compensate the latter and still have more besides. The defendant in the car accident example is harmed by the court's rejection of the contributory negligence defense in favor of the new rule of comparative negligence. The beneficiaries, however, include not only the plaintiff in this dispute, but also all drivers who prefer that future accidents be

20. The expected liability equals by definition the probability times the extent of liability. The probability of the plaintiff being found liable, and the extent of his liability, are presumably less under negligence with a defense of contributory negligence than under comparative negligence.

21. The usual reason given for such a preference is that comparative negligence is not so harsh as the all-or-nothing rules. In economic jargon, the new rule provides for a superior allocation of risk. 
decided under the new rule. If the harm caused by the change is less than the benefit, everyone affected by it could be made better off, at least in principle. Such a change is called a hypothetical Pareto improvement because the Pareto standard can be satisfied in principle by an appropriate redistribution of the gains. ${ }^{22}$ Since the redistribution is only hypothetical, this standard allows changes that make some people worse off. This is the standard invoked in cost-benefit analysis, according to which projects are undertaken if the benefits exceed the costs to whomever they accrue.

Cost-benefit analysis is closely related to measures of national wealth like Net National Product. In cost-benefit analysis, the value of goods and services is measured by the amount that people are willing to pay for them. The Net National Product is measured by a nation's production of goods and services valued at market prices. When markets are perfectly competitive, the amount that people are willing to pay for goods exactly equals the price at which they are sold in the market. ${ }^{23}$ So cost-benefit analysis has maximizing national wealth as its goal when prices are given by perfectly competitive markets. When markets are imperfect, however, the market prices of goods fail to measure their true value. ${ }^{24}$ For example, the price that a monopolist charges for goods is more than people would be willing to pay for the resources used to make them. Cost-benefit analysis tries to take account of such market failures, whereas relatively simple measures of wealth, such as Net National Product, omit in practice many of the corrections that are desirable in principle. The measure of value in cost-benefit analysis is sufficiently similar to Net National Product that the term "wealth" can be applied to both of them. Net National Product can thus be regarded as a simple way to measure the flow of wealth based on prices in actual markets, and cost-benefit analysis can be regarded as a sophisticated way to measure wealth based on the prices that would prevail if competition were perfect.

\section{B. The Foundational Argument}

Two concepts of efficiency have been sketched-the literal Pareto standard and wealth maximization. To assess whether a change is an improvement by either of these standards, there must be an initial distribution of resources against which to measure whether people are better off or worse off. An

22. Different concepts of economic efficiency are explained as they apply to law by Jules Coleman in Efficiency, Exchange, and Auction: Philosophical Aspects of the Economic Approach to Law, 68 Calif. L. Rev. 221 (1980), and Efficiency, Utility, and Wealth Maximization, 8 Hofstra L. Rev. 509 (1980). The hypothetical Pareto improvement standard also is called the Kaldor-Hicks measure, or compensating variation, or the equivalent variation.

23. In competitive markets for goods sold in continuously variable quantities, the rational consumer purchases the good until the marginal benefit exactly equals the price, and producers supply the good until the price exactly equals the marginal cost, so marginal benefit equals marginal cost.

24. Market failures are conventionally distinguished into monopoly, externality, and asymmetric information. For a discussion of the market failures approach to regulation, see C. SchulTze, supra note 12. For a balanced discussion of the problems that consumer's surplus raises for law, see Harris, Ogus \& Phillips, Contract Remedies and the Consumer Surplus, 95 LAw Q. REv. 581 (1979). 
initial distribution of resources is the Archimedian point by which the efficiency analysis is levered. If this point detaches itself and moves, the comparison of alternative policies in terms of their relative efficiency becomes incoherent.

To illustrate, suppose that the initial state of the economy is labelled A; suppose further that a policy is contemplated to change the economy to state B. To decide whether to adopt this policy, a cost-benefit analysis is conducted and it is determined that the benefits of a change from $A$ to $B$ exceed the costs. The policy is, consequently, adopted. Here is the puzzle. It is possible in principle that a new cost-benefit study would yield the conclusion that the benefits of a change from $B$ back to $A$ also exceed the costs. In brief, the conventional measure of wealth is reversible in pairs, at least in principle. ${ }^{25}$

A standard of choice that urges the decisionmaker to do actions and then immediately undo them is useless. Cost-benefit analysis is useful, not useless, because reversibility does not occur so long as the analysis is confined within its proper scope. Seeing why reversibility can occur explains the appropriate scope of its application. In cost-benefit analysis, different goods are combined into an aggregate measure of value by assigning prices to them that would prevail under perfect competition. The prices that would prevail under perfect competition, however, depend upon the distribution of income. To illustrate, in a society where a few people have a lot of money, luxury goods like chinchilla coats will be in demand. In contrast, in an egalitarian society where everyone has a little money, there will be less demand for luxury goods. The level of demand affects prices, especially in the short run. So the price of chinchilla coats will probably be lower when there is more equality. Reversibility can arise because the comparison is based upon different income distributions and, consequently, different prices are used to add up the total value of goods constituting society's wealth. ${ }^{26}$

25. It is, consequently, intransitive in triples as well.

26. The technical explanation is as follows: The initial state $A$ involves a specific distribution of income. Given this income distribution, perfect competition would result in a specific set of market prices. Assume these prices are used to measure the total value of the goods and services in state $A$ and state B, with the conclusion that wealth is greater in B than in A.

Now reverse the process. The initial state is now $B$, which involves a specific distribution of income. With this income distribution, perfect competition would result in a specific set of market prices, which are not necessarily the same price identified in the preceding paragraph. Suppose these prices are used to measure the total value of the goods and services in state B and state A. It is possible that this comparison will lead to the conclusion that wealth is greater in $B$ than in $A$.

In this example, wealth is greater in $A$ than in $B$ at one set of prices, and the opposite is true at the other set of prices. The standard of wealth does not provide any basis for determining which set of prices is best for aggregating goods and services. In order to identify the best set of prices, it may be necessary to identify an ideal distribution of income. (And the ideal distribution of income would have to be identified independent of prices in order to avoid circularity in the arguments.) Philosophically, this implies that measuring the quantity of wealth independent from its distribution involves an inconsistency.

This problem has a long history. See, e.g., Scitovsky, A Note on Welfare Propositions in Economics, 9 Rev. Econ. Stud. 77 (1941); Samuelson, Evaluation of Real National Income, 2 Oxford Econ. PAPERS, NEW SERIES 1 (1950). The whole issue has been clarified by the use of the expenditure function. See Diamond \& McFadden, Some Uses of the Expenditure Function in Public Finance, 3 J. PuB. Econ. 3 (1974); Cooter, A New Expenditure Function, 2 ECoN. LeTtERs 103 (1979). 
Here is an example from law. Suppose that a noble family has been impoverished to the point that only their estate, Blackacre, remains as testimony to their former grandeur. The heir to Blackacre would not contemplate its sale for less than $\$ 10$ million dollars, even though its market value is only $\$ 2$ million. If Blackacre were taken from the current heir, she could not afford to pay even as much as its market value to buy it back. Suppose the state has determined that a project to build a highway through Blackacre is viable only if the value of the estate does not exceed $\$ 3$ million. How should Blackacre be valued in a cost-benefit analysis? If the initial distribution allocates Blackacre to the heir, a cost-benefit analysis should assess its value at $\$ 10$ million. If, however, the initial distribution allocates Blackacre to someone other than the heir, a cost-benefit analysis should assess its value at $\$ 2$ million. Thus, the initial distribution of resources affects prices, and prices determine the viability of the project.

The efficiency analysis provides a coherent guide to choice relative to a particular specification of the income distribution. The possibility of reversibility demonstrates that the efficiency analysis presupposes an initial distribution of income. For purposes of the economic analysis of law, the initial distribution must include fundamental legal rights and duties. The initial distribution of fundamental legal rights and duties affects the amount that people would be willing to pay to acquire secondary rights or to be free of secondary duties. An efficiency analysis that places values on rights and duties thus presupposes an initial distribution of normative resources. If the efficiency analysis contemplates modifications in fundamental rights and duties, the problem of reversibility may arise, just as it may arise in a costbenefit analysis of a project that is large enough to affect underlying prices.

The initial distribution may be described by an historian, explained by a social scientist, or evaluated by a philosopher. Theories that describe, explain, or evaluate an initial distribution of normative resources are logically prior to an efficiency analysis. This can be called the foundational argument for the priority of fundamental legal values over efficiency.

\section{Liberty and Pareto Efficiency}

To explore the complementary relationship between fundamental legal values and efficiency, consider the preceding accounts of liberty. Suppose Mill's concept of liberty-as-no-interference is used to identify a maximum set of basic liberties. Some laws will be directed towards defining and protecting these liberties. Other laws will be directed towards maximizing their value. The economic analysis will be most useful in understanding the latter.

A specific illustration is provided by liability rules in tort law. Mill's theory suggests that people should be free from interference by others. The law of torts prescribes the boundary between freedom and responsibility to others. Individual freedom runs out and responsibility begins, according to Mill's principle, at the point where one person's action harms another person. To protect the right to be free from interference, the law must prescribe a remedy 
to use when one person accidentally harms another. The fundamental right, however, may be protected by a variety of tort rules, such as comparative negligence or negligence with a defense of contributory negligence. A strong reason for choosing a particular rule is to maximize the value of the underlying rights as assessed by the people to whom they belong. If the new rule of comparative negligence is a Pareto improvement over the old rule of negligence with a defense of contributory negligence, this is a strong reason for adopting the new rule.

A similar argument could be developed for other aspects of the common law. To illustrate, ownership of property traditionally encompasses the right to possess, use, exclude others from using, bequeath, and sell property. These rights create a zone of privacy in which owners can exercise their will over things without being answerable to others. The idea of property thus carries with it a commitment to diffusing power among owners, whether individuals or organizations, rather than concentrating this power among officials. Property can be defined as the institution that, by allocating things to people, gives people liberty over things.

Although the right to property is fundamental, it is also consistent with a variety of rules concerning ownership. For example, public corporations are owned by their stockholders. Suppose that a corporation is the target of a hostile takeover bid in which the buyers plan to replace management and alter corporate strategy. Should the acquiring firm be permitted to offer a higher price to the sellers of the first $51 \%$ of the stock than to other stockholders? Or should the acquiring firm be required to offer the same price to every willing seller? If the law answers this question by choosing the more efficient rule, the aggregate value of stock will be maximized, thereby maximizing the aggregate value of the underlying rights.

Another example comes from the law of contracts. The enforcement of promises enables people to coordinate their behavior and plan for the future. In economic jargon, contracts expand the opportunity set. In loftier language, contracts are private statutes that people voluntarily enact to govern their future relations. The power of private legislation is so important that it may be regarded as a fundamental legal value. To protect this value, the law must prescribe remedies for broken promises. The standard remedy in America is damages. There are, however, various ways to compute damages, notably the expectation and reliance measures. Either measure affords protection for the underlying rights. If it can be shown that one damage measure-say, the expectation measure-maximizes the value of the underlying rights as assessed by the people to whom they belong, this demonstration would provide a strong reason for the courts to choose that damage measure rather than another.

If all legal disputes deeply implicated fundamental values, theories about these values would dictate the correct solution to all legal problems. There would be no scope for the efficiency analysis. The preceding examples show that some important legal disputes do not implicate fundamental legal values 
so deeply as to preclude the efficiency analysis. Exactly how much room a theory of fundamental values leaves for an efficiency analysis depends upon the particulars of both. The fundamental value that concerns this article is liberty, and the two concepts of efficiency discussed so far are Pareto efficiency and wealth maximization. This article will show that a theory of liberty leaves ample scope for an analysis based upon Pareto efficiency, and less scope for an analysis based upon wealth maximization. A legal system can maximize liberty and adopt a version of the Pareto standard without conflict, but a legal system that tries to maximize liberty and the nation's wealth will encounter conflicts between these goals.

\section{Prospective Pareto Efficiency}

Assume that a set of rights and duties is identified that maximizes liberty according to one of the preceding conceptions. These rights and duties constitute an initial distribution of normative resources. The literal Pareto standard commends changes that make everyone better off and no one worse off relative to this initial distribution of normative resources. The concept of liberty is based upon respect for individual freedom and the concept of Pareto efficiency is based upon respect for individual values, so it is difficult to imagine how a conflict could arise between liberty and Pareto efficiency. ${ }^{27}$

The objection to the literal Pareto standard is not that it conflicts with liberty, but that few changes benefit someone without harming anyone. The literal Pareto standard is impractical as a guide to policy. For example, the distributive consequences of litigation make the literal Pareto standard impractical as a guide for adjudication. The standard solution to this problem, which has already been discussed, is to abandon Pareto efficiency and move to a conception of wealth maximization. There are, however, many more objections to wealth maximization as a goal of the courts than to Pareto efficiency. The economic analysis of law should avoid wealth maximization whenever possible.

There is, fortunately, an intermediate alternative that could prove important in law. The literal Pareto standard is impractical because of the retrospective aspect of litigation. When viewed retrospectively, the distributional consequences of dividing the stakes in litigation cause the parties to disagree about the rule that should be applied to decide their dispute. There are circumstances, however, in which both parties would prefer to decide future disputes by one rule rather than another. To illustrate, in the preceding example from torts, both parties to the litigation prefer for liability in future accidents to be governed by the rule of comparative negligence, as opposed to the rule of negligence with a defense of contributory negligence. A rule that everyone prefers to control future disputes relative to the alternatives that are within the court's contemplation

27. This generalization holds up in spite of some deviant examples, such as a person being prevented from voluntarily selling himself into slavery. 
can be called Pareto efficient from a prospective viewpoint, or prospectively Pareto efficient. ${ }^{28}$ The approach to adjudication preferred in this paper is to resolve disputes by applying the Pareto standard to their ex ante aspect. The commended principle of adjudication is to resolve disputes whenever possible by the rule that both parties would prefer to apply prospectively.

Standard philosophical objections to prospective jurisprudence are not discussed here. ${ }^{29}$ Instead, the objection to be addressed is that, like the literal Pareto standard, there are many situations in which the prospective Pareto standard is impractical. The prospective Pareto standard can only resolve legal disputes in which the parties are symmetrically situated with respect to the future. "Symmetrically situated," in the context of tort law, means that everyone faces similar probabilities of being an injurer or a victim in a future accident. To illustrate by the preceding example, suppose a collision between two automobiles damages one of them. A dispute arises in which the stakes equal the damage to the car. The allocation of the stakes in the dispute will be at least as favorable to the defendant under the rule of negligence with a defense of contributory negligence as under the rule of comparative negligence. So the defendant prefers dividing the stakes according to the rule of negligence with a defense of contributory negligence, whereas the plaintiff prefers dividing the stakes according to the rule of comparative negligence. Where future accidents are concerned, however, the current defendant may feel that he is equally likely to be a future plaintiff or a future defendant, and likewise for the current plaintiff. Since the parties face similar uncertainty about their future identities, the best prospective rule for one of them is probably also the best for the other. They may both prefer the rule of comparative negligence to resolve all future disputes involving automobile accidents. In these circumstances the commended standard of adjudication requires allocating the stakes in an accident that has occurred according to the rule that the parties would prefer for allocating future losses.

When the parties' situations are asymmetrical, however, the prospective Pareto standard cannot choose among alternative rules because the parties do not agree about the best rule to apply to future cases. To illustrate, suppose

28. Cooter and Ulen argue that the rule of comparative negligence is prospectively pareto superior to the old rule of negligence with a defense of contributory negligence. See An Economic Case for Comparative Negligence, 63 N.Y.U. L. REv. (1988).

29. The prospective Pareto standard is unlikely to run afoul of liberty, but it may run afoul of fairness. A variety of philosophical arguments have been made against courts taking a forwardlooking viewpoint when resolving disputes. To illustrate, prospective decisionmaking by courts appears objectionable on the same grounds as retroactive legislation: People are held responsible for failing to meet legal standards that did not exist when they acted.

An answer to this objection requires qualifying the prospective Pareto standard by an account of its relationship to pre-existing norms. In so far as the standard is embodied in pre-existing norms, the norms are not applied retrospectively.

These arguments are familiar to followers of the debate over utilitarian jurisprudence. Utilitarianism, being an ex ante standard, is vulnerable to the charge of retroactive legislation. At the deepest level, this is a debate about whether utilitarianism has only one rule-maximize utilitywhich precludes all others by making them too tentative, or whether the one rule gives rise to many specific rules. The view that utilitarianism gives rise to many rules is defended by John Rawls in Two Concepts of Rules, 64 PHiL. Rev. 3 (1955). 
that a consumer can confidently predict that he will not become a manufacturer or a significant shareholder in corporations. This consumer and manufacturers are asymmetrically situated. Their interests may diverge, at least in the short run, concerning liability for injuries caused by defective products. The consumer may prefer for future disputes concerning consumer product injuries to be resolved by a rule of strict liability, whereas manufacturers may prefer for all future disputes to be resolved by a rule of negligence. ${ }^{30}$

\section{E. Liberty and Wealth}

The range of practical application of the prospective Pareto standard is limited to cases in which the parties are symmetrically situated with respect to future losses. This range is, fortunately, large enough to encompass many of the impressive results in the economic analysis of law. There are, however, other situations such as the example of a short run perspective on defective products, in which prospective Pareto efficiency does not offer a practical guide. In these circumstances, the economic analysis of law must fall back upon wealth maximization as its normative principle. Unlike Pareto efficiency, wealth maximization can conflict with liberty. This section characterizes the conflict.

When legal rights are assigned to individuals solely in order to maximize national wealth, all the rights of individuals are contingent upon their contribution to a social goal. Individual rights do not seem to be so tentative in American law. A powerful critique of utilitarian jurisprudence has developed in recent years based upon the insight that individual rights should be fundamental in law, not contingent upon their contribution to a social goal. To illustrate, contrast the kind of property law that flows from wealth maximization as opposed to individual liberty. In a theory of liberty, the purpose of the institution of property is to create a zone of private discretion over resource allocation. According to this approach, the owner's right to dispose of his own property does not depend upon whether he does anything socially useful with it. In contrast, in a theory of wealth maximization, the purpose of the institution of property is to maximize the wealth of the nation. According to this approach, the owner's right to dispose of his own property is contingent upon it being put to the highest valued use. For example, suppose that national income can be increased by government regulation such as prescribing who may inherit land, restricting private contracts, or ordering farmers to plant some crops and not others. The wealth maximization approach does not recognize that these policies involve a sacrifice of individual liberty.

30. This example may require a short run perspective or an element of monopoly because, in the long run under perfect competition, manufacturers enjoy the ordinary rate of return on capital regardless of the law, and consumers pay the full cost of liability claims against manufacturers through higher prices of manufactured goods. 
From the viewpoint of wealth maximization, the only reason the law recognizes individual liberty is to further an aggregate goal. This fact is partially disguised by the belief among economists that unfettered private enterprise is more efficient than government regulation. This belief implies that circumstances will rarely arise in which wealth can be increased by sacrificing individual liberty, ${ }^{31}$ so the proponents of wealth maximization seldom acknowledge that their theory makes individual rights contingent upon their contribution to a social goal. ${ }^{32}$

The relationship between wealth and individual liberty can be explicated by representing the trade-off graphically. The horizontal axis in Figure 5 depicts different amounts of liberty, ranked from low to high. The rank order is supplied by one of the three conceptions of liberty developed in the preceding section of this paper. The vertical axis represents different amounts of wealth. Any point on the graph thus represents a combination of wealth and liberty.

The curved lines in the graph represent utility curves of a decisionmaker. If the axes in Figure 5 were labelled, say, apples and oranges, instead of liberty and wealth, it would look like the graph used to introduce utility theory in any introductory course on economics. In such a representation, the points on any single utility curve represent different bundles of goods towards which the decisionmaker is indifferent. In Figure 5, for example, the decisionmaker is indifferent between the combination of liberty and wealth represented by points $\mathrm{A}$ and $\mathrm{B}$.

To interpret Figure 5, consider the distinction between the basic liberties, which the decisionmaker values most, and secondary liberties, which she values less. The horizontal axis of the graph is drawn on the assumption that the liberties are ordered from the most important on the left to the least important on the right. This fact is indicated in Figure 6 by drawing a vertical line separating the more basic liberties from the rest. The exact location of this line is arbitrary, like the boundary between your face and the back of your head. Another line, also indicating an arbitrary boundary, is drawn horizontally in Figure 6 to bisect the vertical axis. This line distinguishes levels of wealth into zones of moderate scarcity and severe scarcity.

These two lines divide the graph into four quadrants that are labelled $Q 1$, Q2, Q3, and Q4 in Figure 6. The point to note is that in Q1, where wealth is adequate but the decisionmaker is deprived of some of the basic liberties, the indifference curves are almost vertical. In this zone liberty precedes wealth in the preferences of the decisionmaker. To be more precise, the decisionmaker in Q1 would not trade a small amount of liberty for a large increase in wealth.

31. See, e.g., G. Stigler, The Citizen and the State (1975).

32. There is another tradition in economics, contradictory to the first, which is pessimistic about unfettered private activity and optimistic about government's ability to regulate markets. The second tradition holds that circumstances will often arise in which wealth can be increased by government. See, e.g., A. Pigou, The Economics of Welfare (1978). Coase's classic The Problem of Social Cost, supra note 12, advocates cost-benefit analysis and also attacks Pigou. Thus, Coase advocates wealth maximization as the goal of the law and also doubts that government regulation can increase wealth. 
FigURE 5

Wealth, Liberty, and Preferences

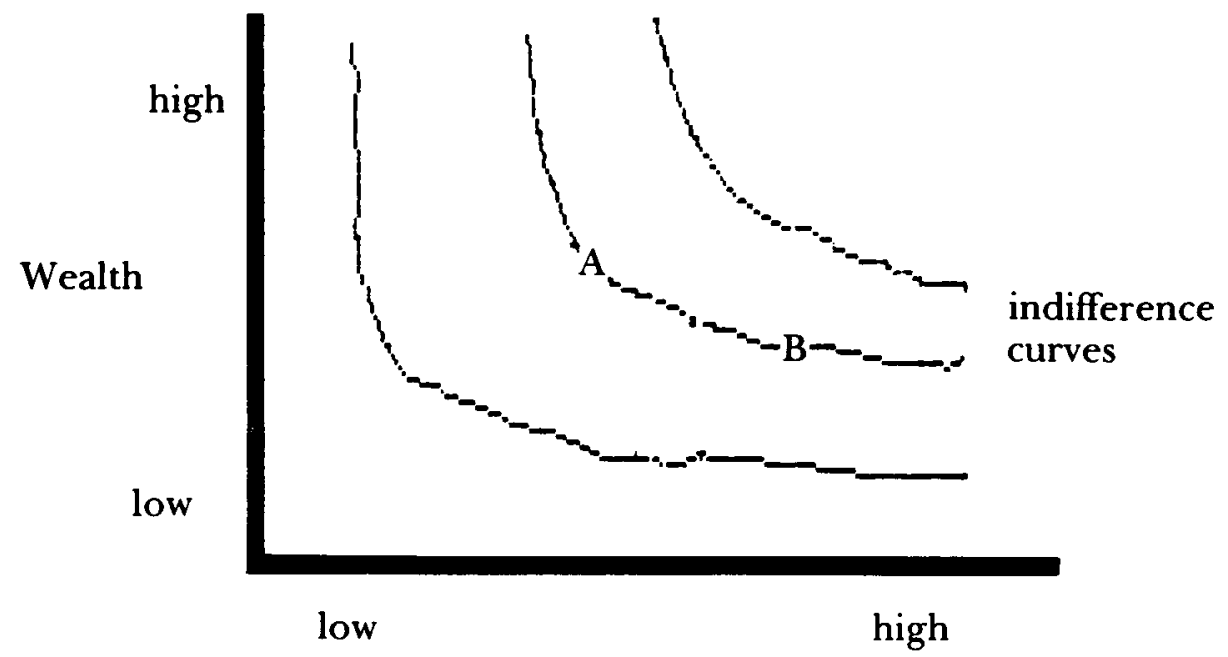

Liberty

Q1 is thus the zone in which the decisionmaker maximizes liberty and gives little weight to wealth.

The opposite is true in quadrant Q3, where the decisionmaker enjoys the basic liberties but wealth is severely scarce. In $Q 3$, the utility curves are horizontal, indicating that the decisionmaker would not trade a small amount of wealth for a large increase in liberty. Q3 is thus the zone in which the decisionmaker maximizes wealth and gives little weight to liberty.

In quadrant $\mathrm{Q} 2$, there is both adequate wealth (moderate scarcity) and adequate liberty (the basic liberties), so the decisionmaker is prepared to trade off additional increments of wealth and liberty. In this quadrant the decisionmaker does not pursue either of the pure goals-maximizing wealth or maximizing liberty-but rather pursues a mixed goal of maximizing a weighted combination of the two.

This graph can make sense of Rawls' claim that, under conditions of moderate scarcity, a rational person is unwilling to sacrifice basic liberty in order to obtain a large increase in wealth (lexical priority of liberty). If the decisionmaker is contemplating a trade-off between wealth and basic liberty, and this choice is being contemplated under conditions of moderate scarcity, the choices are located in $Q 1$. In $Q 1$ the indifference curves are almost vertical, which indicates that the decisionmaker would not trade a small amount of liberty for a large increase in wealth.

The most basic liberties in law are conventionally grouped into broad areas, such as freedom of religion, freedom of speech, freedom of the press, freedom of political association, and the right to property. Disputes in constitutional law often concern these basic liberties. In these disputes there may be a trade-off between basic liberty and wealth. According to Rawls' theory, such disputes should be resolved by favoring basic liberty and 


\section{FIGURE 6}

Four Quadrants

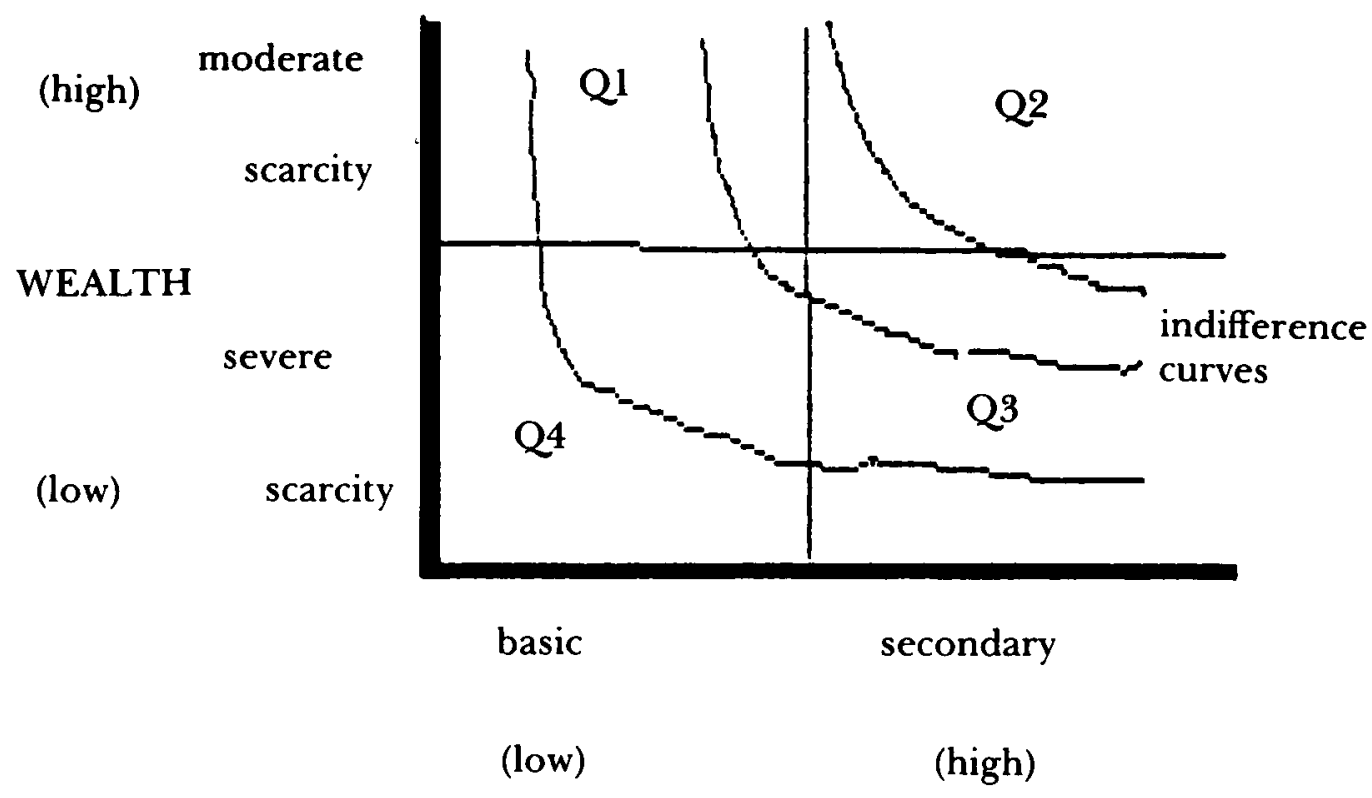

LIBERTY

disfavoring wealth. The argument that courts actually favor liberty over wealth as values for deciding disputes will be called the valuational argument.

The dispute is fundamental when it affects a basic liberty. Choices between basic liberty and wealth under conditions of moderate scarcity are depicted in $\mathrm{Ql}$ of Figure 6 . In this zone, basic liberty is not traded for wealth. Assuming moderate scarcity, the judge who finds himself deciding a fundamental case may properly decide to increase basic liberty rather than increase wealth. The valuational argument-that liberty controls adjudication when choices concern basic liberties and wealth-applies in Q1.

In practice much adjudication concerns choices between secondary liberties and wealth, as opposed to the choice between basic liberties and wealth. In such circumstances where choices are not fundamental, the judge may appropriately think of the choice as being in Q2. In this zone liberty and wealth trade off.

While Figure 6 depicts the preference of a decisionmaker faced with choices between wealth and liberty, it does not depict the constraints. The access of a society to different combinations of wealth and liberty depends upon its technical and scientific development, its resource base relative to its population, and its institutions and traditions of government. Americans have grown accustomed to a level of wealth that some characterize as moderate scarcity and others characterize as affluence. In any case, Americans have not recently faced conditions of severe scarcity. Furthermore, our institutions and traditions of government have typically enabled most citizens to enjoy the basic liberties. The judiciary is instrumental in protecting and strengthening 
our basic liberties. From time to time judges must decide cases affecting basic liberties. In these decisions, the alternatives lie in $\mathrm{Q} 1$, where liberty is not sacrificed for wealth.

It is, however, within our capacities as a nation to provide both liberty and prosperity. Thus, the frontier of the opportunity set faced by judges is not situated in Q1. Rather, the outer boundary of feasible choice is situated in Q2, where prosperity and liberty are combined in full measure. In this zone there is a trade-off between secondary liberties and wealth. How severe is this trade-off in practice? As explained above, the severity of the trade-off looks different depending upon the concept of liberty and the tradition of economic thought of the viewer. If the relevant concept is liberty-as-no-interference, the economic tradition that regards unfettered capitalism as more productive than any form of government regulation detects no trade-off, whereas the economic tradition that stresses the role of government in correcting market failures will recognize a trade-off.

Before leaving this discussion of liberty, it is helpful to suggest why the argument about trade-offs remains unchanged if "utility" is substituted for "wealth." The wealth maximizing approach proposes structuring law to maximize social value as measured by competitive market prices. Structuring law to maximize social value is the same principle advocated much earlier by Bentham in The Principles of Morals and Legislation. ${ }^{33}$ The difference is not the general goal of maximizing social value, but the specific interpretation of it, whether wealth or utility. The same amount of wealth can yield different amounts of utility, depending upon how the wealth is distributed. According to the utilitarian tradition in economics, ${ }^{34}$ an additional dollar yields more utility to a poor person than to a rich person, so redistribution of wealth to the poor increases total utility, provided that not too much wealth is lost in the process. A discouraging fact about the utilitarian tradition is its failure to measure utility with sufficient accuracy to provide a clear guide to income redistribution. Some economists are content with the idea that the marginal utility of money, like the border of Burma, is meaningful but uncertain. Others have held that the marginal utility of money has not been operationalized because it is meaningless or, at least, it has no scientific meaning.

This debate among economists about whether social value should be measured by wealth or utility, which often resembles a family feud, is unimportant to this paper, because most arguments against wealth maximization apply equally to utility maximization. The preceding graphs depict wealth on the horizontal axis, but "utility" could be substituted for "wealth" without further changes. Both approaches conflate individual preferences in order to arrive at a standard of social value. In one case, the conflation uses market prices, and in the other case the conflation weights

33. See supra note 8 .

34. For a discussion of this tradition, see Cooter \& Rappoport, Were the Ordinalists Wrong About Welfare Economics, $22 \mathrm{~J}$. Econ. Literature 507 (1984). 
market prices according to the wealth of the affected classes. The view taken in this paper is that respect for liberty prompts a reluctance to conflate individual preferences by either method.

\section{IV}

\section{ConClusion}

An efficiency analysis of law presupposes an initial distribution of rights and duties, which corresponds to the initial distribution of income in an efficiency analysis of markets. Given the initial distribution of normative resources, an efficiency analysis of law shows how to maximize its value as measured by the preferences of the people to whom the rights and duties are distributed.

Liberty is such a fundamental legal value to Americans that some philosophers believe the law should maximize it. Three different concepts of such a maximum set were explained in this article. Under any of these conceptions, liberty and Pareto efficiency are complementary, not competing, objectives.

Wealth maximization is, however, far more likely than Pareto efficiency to conflict with individual liberty as a goal. The conflict is more likely because individual rights are regarded as contingent upon their contribution to maximizing the nation's wealth. This way of thinking makes individual rights more tentative and precarious than they have usually been regarded in American political philosophy. A philosophy more in keeping with American traditions resolves conflicts between basic liberties and wealth in favor of the former, and trade-offs are allowed between secondary liberties and wealth.

Given these facts, the economic analysis of law should rely upon the Pareto standard whenever practical. The Pareto efficiency concept can be applied to the prospective aspect of cases in which the litigants are symmetrically situated with respect to an uncertain future. When the Pareto standard is impractical, however, the economic analysis must fall back upon wealth maximization, but in doing so its proponents should be aware that their models become susceptible to many difficulties and objections. 
HeinOnline -- 50 Law \& Contemp. Probs. 1641987 